\title{
Patients with dementia and atrial fibrillation are less likely to receive direct oral anticoagulants
}

\author{
(DIvana Jurin ${ }^{1 *}$, \\ (D) Marko Lucijanić', \\ (D) Vedran Radonić2 \\ (1)Tomislav Letilović ${ }^{2}$, \\ (D)Jasmina Ćatić', \\ (iD) Ana Jordan', \\ (iD) Petra Vitlov' ${ }^{\text {, }}$ \\ Dirzal Hadžibegović ${ }^{1}$
}

'University Hospital Dubrava, Zagreb, Croatia

2University Hospital Merkur, Zagreb, Croatia

\section{RECEIVED:}

December 6, 2020

ACCEPTED:

December 18, 2020

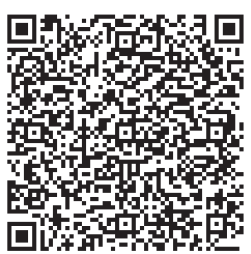

$\square$ Cardiologia Croatica 2021;16(1-2):60.
KEYWORDS: atrial fibrillation, dementia, direct oral anticoagulants.

CITATION: Cardiol Croat. 2021;16(1-2):60. | https://doi.org/10.15836/ccar2021.60

*ADDRESS FOR CORRESPONDENCE: Ivana Jurin, Klinička bolnica Dubrava, Av. Gojka Šuška 6, HR-10000 Zagreb, Croatia. / Phone: 385-98-559387 / E-mail: ivanajurin1912@gmail.com

ORCID: Ivana Jurin, https://orcid.org/0000-0002-2637-9691 • Marko Lucijanić, https://orcid.org/0000-0002-1372-2040 Vedran Radonić, https://orcid.org/0000-0002-2115-2826 • Tomislav Letilović, https://orcid.org/0000-0003-1229-7983 Jasmina Ćatić, https://orcid.org/0000-0001-6582-4201 • Ana Jordan, https://orcid.org/0000-0001-5610-6259 Petra Vitlov, https://orcid.org/0000-0001-6983-1409 • Irzal Hadžibegović, https://orcid.org/0000-0001-9139-5009

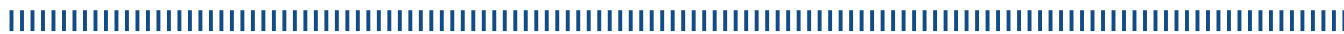

Objective: Atrial fibrillation (AF) has been associated with dementia, even in patients without prior stroke and the pathogenesis that correlates the two entities is multifactorial. Imaging studies have shown that structural cerebral changes are common in patients with AF so it was thought that treatment with oral anticoagulants should protect against small emboli which causes microinfarctions that eventually lead to cognitive deterioration. Patients with dementia are less likely to receive anticoagulant treatment although previous studies have reported that AF patients on anticoagulant treatment at baseline had a $29 \%$ lower risk of dementia. ${ }^{1}$ To investigate prescription patterns of anticoagulation therapy in patients with AF and dementia as well as incidence of dementia in the patient cohort.

Patients and Methods: A total of 1217 patients with non-valvular AF from two institutions were retrospectively evaluated. Physical examination, clinical history and medication profile were obtained at baseline.

Results: Median age of our cohort was 71 years. A total of 162/1217 (13.3\%) patients were diagnosed with dementia. Patients with dementia were significantly older, were more likely to be of female gender, more likely to have diabetes mellitus, prior stroke/TIA, heart failure, peripheral artery disease, osteoporosis, thyroid disease, lower eGFR, lower height, lower weight, lower LVEF, lower hemoglobin, higher CRP, higher leukocytes, to take higher number of drugs in general and higher number of psychiatric drugs. Median follow-up of our cohort was 53 months. In univariate analyses among unselected AF patients, patients with dementia were significantly more likely to experience inferior overall survival ( $\mathrm{HR}=15.3 ; \mathrm{P}<0.001)$, shorter time to thrombosis ( $\mathrm{HR}=8.4 ; \mathrm{P}<0.001)$, shorter time to major bleeding $(\mathrm{HR}=4.13 ; \mathrm{P}<0.001)$ and shorter time to first fall $(\mathrm{HR}=2.36 ; \mathrm{P}<0.001)$.

Conclusion: Our findings speak in support of increased thrombotic and mortality risks in patients with dementia, possibly due to inadequate anticoagulation and higher number of comorbidities. Therefore, our suggestion is that physicians should prescribe more often DOACs in patients have dementia or higher risk of developing dementia.

LITERATURE IIIIIIIIIIIIIIIIIIIIIIIIIIIIIIIIIIIIIIIIIIIIIIIIIIIIIIIIIIIIIIIIIIIIIIIIIIIIIIIIIIIIIIIIIIIIIIIIIIIIII

1. Friberg L, Rosenqvist M. Less dementia with oral anticoagulation in atrial fibrillation. Eur Heart J. 2018 Feb 7:39(6):453-460. https://doi.org/10.1093/eurheartj/ehx579 